\title{
Follow the yellow brick road: The passeur, the gatekeeper and the young migrant film-maker
}

\author{
Stephanie Hemelryk Donald* - University of Lincoln, UK
}

\begin{abstract}
In the first part of this article, the author reflects on her experience of making filmmaking workshops with young people in Australia, China and the UK an integral component of a research project on the representation of child migrants and refugees in world cinema. She then sets her approach to these workshops in the context of Alain Bergala's ideas about film education, of which she had initially been unaware. In discussing a couple of further workshops that she ran in the UK and Australia as part of the 'Cinéma, cent ans de jeunesse' programme, she focuses particularly on the benign or obstructive role of institutional gatekeepers, who act as intermediaries or agents determining the terms of access to children and young people for film educators, researchers and practitioners. The legal, protective and ethical dimensions of the relationship between educator, gatekeeper and participating students are discussed. The article cites cases in which the interaction worked well, and others in which it proved problematic. The functions, responsibilities and potential drawbacks of gatekeepers are compared with Bergala's conception of the pedagogic role of the passeur - a figure who also holds power in relation to young people's access to film and film-making, but one that connotes positive, even magical, properties.
\end{abstract}

Keywords: gatekeepers; co-creation; migrants and refugee childhood; Oz; passeur, l'intervalle

Near the beginning of The Cinema Hypothesis, Alain Bergala (2016: 12) explains how, in his novelistic narration of his own life, he was 'saved twice: by schooling and by cinema'. That memory strikes a chord. In my case, educational deliverance came through studying Chinese at university, an experience that realigned my intellectual and imaginative horizons, decentring Europe and instilling a multinodal global perspective on art and culture. Bergala's (ibid.) recollection of cinema entering his life, 'at the heart of a sad and anxious childhood, like a lifeline which I knew, from very early on, would be my salvation', brought to mind my earliest memory of cinema. In the mid-1960s, aged about 3, I was in a large cinema in the English port city of Plymouth watching the core film that 'saw my childhood': The Wizard of Oz (1939). At the point when the Wicked Witch of the West's enormous green face filled the screen, I took to my heels and fled from the auditorium, outraged and terrified at once. I have no recollection of how I was retrieved, or of whether I saw the rest of the film. Nor, however, was I told that I was wrong to run for my life, in my personal little re-enactment of cinema's genesis, as the audience recoiled from the oncoming train in L'Arrivée d'un train en gare de La Ciotat (The Arrival of a Train, 1896). From this somewhat traumatic introduction to the emotional and visceral power of film, I think, came the liberating understanding that there was no protection from fear 
except for my own capacity to make a run from it and, subsequently, to return and take another, closer look at what prompted my fear. To Bergala's two escape routes of school and cinema, I would add a third: theatre. One legacy from ten years spent working as a professional actor, before switching back into an academic career, has been a particular disposition towards any type of 'text', including film. For me, a text is not just there to be read, explicated, theorized and evaluated. My inclination is always to work on the text, preferably collaboratively, so as to derive some sort of performative or creative output from it.

These three forces - the drive for intellectual understanding; imaginative and aesthetic engagement with film; empathetic performance as a way to work through ideas - came together, fifty years after that first encounter with The Wizard of Oz ('the anthem of all the world's migrants', as Salman Rushdie (1992: n.p.) called it), to inspire what I have always thought of as the Dorothy Project (http://dorothyproject.stephaniedonald.info). In conventional research terms, my topic was the representation of migrant and refugee children in world cinema, and that strand of the work duly led to the publication of my monograph, There's No Place Like Home (Donald, 2018). At another level, however, I was aware that the project represented my latest return to $\mathrm{Oz}$ and to Dorothy, still as if my life depended on making sense of her restlessness and her journey. I was trying to understand both the phenomenon of migration and, at the same time, the nature and power of cinema's incursion into my imaginary world. Given this topic, it was, for me, not only a methodological and ethical principle, but also a temperamental inevitability, that the project should involve the direct participation of migrant and refugee children in collaborative projects. The purpose of these projects would be to introduce the children to cinema, to encourage them to engage in film-making, and to enable me to deepen (or thicken) my research by observing their responses. In the next section, I shall take the Chinese workshop as an example of how the children's films did reveal something about their experience of their precarious status as internal migrants. I shall then turn to my UK-based workshops (pre- and post- 'Cinéma, cent ans de jeunesse'), and consider the extent to which they did or did not lend substance to Bergala's worries about the possibility of institutional interference with the liberating cinephilia of the passeur.

\section{The Dorothy Project}

Starting in 2013, working with a number of academic and professional collaborators, I embarked on a series of film workshops with children and young people who had experienced different types of migration in Australia, China and the UK. The first involved high-achieving Indigenous students from rural and remote areas who were boarding in Sydney secondary schools that catered for their specific needs, as well as those of refugee arrivals. The second was designed for domestic migrant children, aged between 7 and 12, attending an NGO-supported after-school drop-in centre in Guangzhou, the sprawling port city 75 miles north-west of Hong Kong on the Pearl River. The third was based in a supplementary Saturday school in London that provides educational, linguistic and cultural support for Afghan refugees and British Afghans.

As the Dorothy Project was largely about journeys and transformations on screen, and the relative nature of space, I began these early workshops with discussions about favourite places, songs and films, and then used paper-based 
reference grids to associate colour with place and mood. The aim was to get participants to think visually. In each case, we talked about ideas of space and time, and reflected on the elastic meaning of words such as 'migration' and 'distance'. We raised the question of how these elasticities might be conveyed cinematically in a single shot or short three-shot sequence. We showed film clips about childhood migrancy, urban wandering and precarious journeys: examples ranged from Jacquot de Nantes (1991), Agnès Varda's homage to the childhood home of her husband, Jacques Demy, and Albert Lamorisse's Le ballon rouge (The Red Balloon, 1956), to Philip Noyce's Rabbit-Proof Fence (2002), and (inevitably) Victor Fleming's The Wizard of $\mathrm{Oz}$ (1939) (Donald, 2015, 2018: 45-69). The question of space was then central to the ways in which, in their own films, the students established relationships between protagonists, between communities represented on screen, and between places that they (or their protagonists) had left and entered on journeys. We did not prompt protagonists for autobiographical information unless they volunteered to share it, and fantasy storytelling was absolutely in order (van Os et al., 2018). Our paradigmatic point of reference was Dorothy's tempestuous transition from Kansas to Oz. Is it the house that moves, or Dorothy's imagination? Is a journey best described one step at a time, or through its moments of crisis? What does the space between protagonists on screen allow us to infer about their challenges in life, and the way they decide to confront them? Students commented on the contrast between the companionably linked arms of Dorothy and her three companions (the Scarecrow, the Tin Man and the Cowardly Lion), and the solitary Wizard hiding behind his curtain.

When it came to the process of making their films, the workshop participants' scope for creative action was inevitably limited by institutional constraints on the availability of time, on their access to space and freedom of movement, and on acceptable levels of noise. Although they were living in a constrained and not altogether welcoming urban setting, it was probably the Chinese migrant children in Guangzhou who enjoyed the greatest freedom relative to their age. The most recent wave of rural migrants to Chinese cities enjoys at best a liminal status, specifically when compared with local families who hold local registration and the civic benefits and advantage that brings. At least the Guangzhou children we worked with were living with their parents; this is not always the case among domestic migrants. Even so, they had all been exposed to displacement and uncertainty: they were living in a condition close to what has been termed 'hyper-precarity' (Lewis et al., 2015: 582-4) or 'life-precarity' (Cangià, 2018). They and their parents had no stable or guaranteed access to labour legislation, city services, affordable schooling, or a permanent right to remain in the cities where they had relocated in search of work. They existed in a vertical hierarchy of non-privilege, subordinated to farmers who had previously occupied urban peripheries where they now lived. The farmers have been forced out by urbanization, but charge extortionate rents for houses built on their once agricultural land. Rural migrants, themselves mainly from farming stock further inland, are forced to pay these inflated rents. The migrants' everyday expectations are therefore precarious, and they are constantly reminded that they do not belong. This produces cumulative economic disadvantage and a social 'life' precarity. The children and their parents are functions of an extended moment of accelerated modernization. There is no defined social or economic future for them beyond this value to the larger society and economy. If the children wish to take major school examinations for college entrance, they have to return to schools in their home villages and towns, which are ill-equipped to prepare them. 
This situation was described obliquely in one boy's film about a bookshop. The owner suddenly leaves, and the boy's parents buy up all the books to support his education. In so doing, they lose all their money and in turn find themselves on the edge of ruin (Donald, 2018: 68). Another child made an animated film, using paper and felt-tip pen, about getting lost in the big city, and then vowing never to return there. Others made films about treasure hunting and finding their own treasured objects. 'I'm digging! I'm digging!', the protagonist calls out, as he scrabbles in a pile of books, before pulling out the little metal hammer he left there as his prop. One might say, 'digging and digging', only to unearth what it is you already possess.

Although these displaced children had only a few streets in which to play, live and attend school, these streets were very much their own. We watched The Red Balloon (1956), in which a boy has an adventure with a balloon/friend in the narrow, winding and sometimes rubble-filled streets of 1950s Paris. His room for manoeuvre is limited, but he shows an intrepid spirit as he explores this neighbourhood. The film ends with his magical ascent to the heavens, buoyed up by hundreds of friendly coloured balloons. The Red Balloon opened the Guangzhou children's eyes to the possibility that their own narrow streets could likewise be a fair location for a 'real film', and that a film protagonist could be an object imbued with human emotion and feeling, like the red balloon (Donald, 2018: 63-7). Getting their hands on cameras and developing their own scripts increased their sense of the space of their neighbourhood being under their eye and within their, admittedly fairly chaotic, visual control. In Bergala's (2016) terms, this might be seen as an example of the power of film as l'altérité - otherness or difference - although it is perhaps telling that none of the participants commented on the escape sequence at the end of the film.

\section{'Cinéma, cent ans de jeunesse'}

In 2015, I had the opportunity to discuss these workshops with Mark Reid, head of UK learning programmes at the British Film Institute. He introduced me to the work of Alain Bergala, inviting me to facilitate a couple of workshops within the 'Cinéma, cent ans de jeunesse' programme. One was in Birkenhead, just across the River Mersey from Liverpool in north-west England. The other took place in 2017 in Menai, a comparatively new and very Anglo dormitory suburb about thirty kilometres south of Sydney in Australia (Bergala, 2016: 48-9; Reid, 2015, 2017). In neither case were the students involved of declared migrant or refugee background.

As I undertook this work, it was reassuring to find that the workshop model that I had devised for the Dorothy Project was not dissimilar to Bergala's approach to film education and engagement in the 'cent ans' programme. In both cases, students and participants watch short films and/or film excerpts with a view to developing a sensitivity to, and respect for, cinema through a specific lens, whether mode of narration or narrative conceit. In my Dorothy Project workshops, the topic was determined by my research focus on children and migration. In 'cent ans', in the French educational tradition of Napoleonic centralization, a new brief (les règles du jeu) is decided annually and prescribed for all participating workshops. This determines the selection of film clips that students view and discuss, the nature of their film exercises, and the topic of their short films. It does not dictate any specific form, tone or content, except for some formal or conceptual reference to the theme. Earlier themes had included colour, place, transition, the weather and le jeu (play). Fortuitously, in 2015 the organizing concept was l'intervalle, or 'the space between', which referred both to the 
framing of figures and objects within a shot, and also the spatial dimension of human relationships, whether at an intimate, personal, social or public level (Reid, n.d.).

The students in Birkenhead learnt about the many possibilities arising from the use of space on screen (emotional, temporal, perceptive, technical) through watching Chaplin, Ozu, Godard and other film 'greats', and they showed real aesthetic courage in their final film, Open Arms (2015), which dealt with the physical and emotional spaces generated by the use of alcohol by young women (www.youtube.com/ watch? $v=q V s z b 6 a M 7 r w)$. From my perspective, the film's formal achievement lay in the way that the students separated protagonists in open space, through screens, and through shots that fragmented and displaced the viewer's orientation to time and place. Their journey, and the discoveries that this made possible, seemed to me very similar to the result of workshops that I had held in China three years earlier (although the children there had been much younger). The Birkenhead group developed and deployed good technical skills that were not available in Guangzhou, mainly as a result of lack of time, equipment and prior knowledge. In both cases, however, the young film-makers elaborated on the space available to them in imaginative and bold appropriations of their environment.

One key element in Bergala's (2016) vision for film education is the inspirational and perhaps somewhat romanticized figure of the passeur, who transports the neophyte into the world of cinephilia, and the ambiguous relationship between the passeur and the established teacher of film in schools (Gibbs, 2018). Teachers may fulfil the role of passeur, but only if they embody not just an appreciation of art, but a passion and excitement that they can convey to others (Bachmann and Zahn, 2018: 80). That is why the 'cent ans' approach leaves room for the prescribed film extracts and examples to be supplemented by a teacher, or, for that matter, by students (Bergala, 2016: 68-9; Bachmann and Zahn, 2018: 84-5).

The power and potential effectiveness of this approach was brought home to me by one memorable session in Birkenhead. Earlier in the week, I had attended a magical seminar on the long take and slow modernity in Kenji Mizoguchi's Zangiku monogatari (The Story of the Late Chrysanthemums, 1939), given by the film scholar Lúcia Nagib. Three days later, as a result, I scrapped the screenings planned for that week's workshop and proposed instead that we watch the long take discussed in Nagib's talk. We - the students, myself, and the professional film-maker working with me - sat in an ordinary classroom with a medium-size screen and poor blackout, on a Saturday morning, watching a black-and-white film, eighty years old, in a language that no one in the room could understand. Yet that clip perfectly exemplified how shifting levels of intimacy and status between protagonists (a male actor and a wet nurse) may be communicated through their changing spatial relationship in a simple sequence of walking and talking within a conceit of collapsed time, and time phased by the soundtrack of night and day street traders. This was the extract, above all others, that took the Birkenhead students to an advanced level of comprehension, as they came to appreciate the power of technical discipline and precise measurement in plotting cinematic space and time to achieve powerful emotional impact and narrative progress. The two shots below are taken from the final sequence of their film Open Arms. The first shows a girl staring across space at her object of desire, alcohol (see Figure 1). The second shows another girl leading her friend - also an addict - to a presumed place of safety (see Figure 2). The trust between them is tenuous, and will be betrayed by the end of the sequence. The extended distance between the protagonists suggests this thinly taut relationship. 


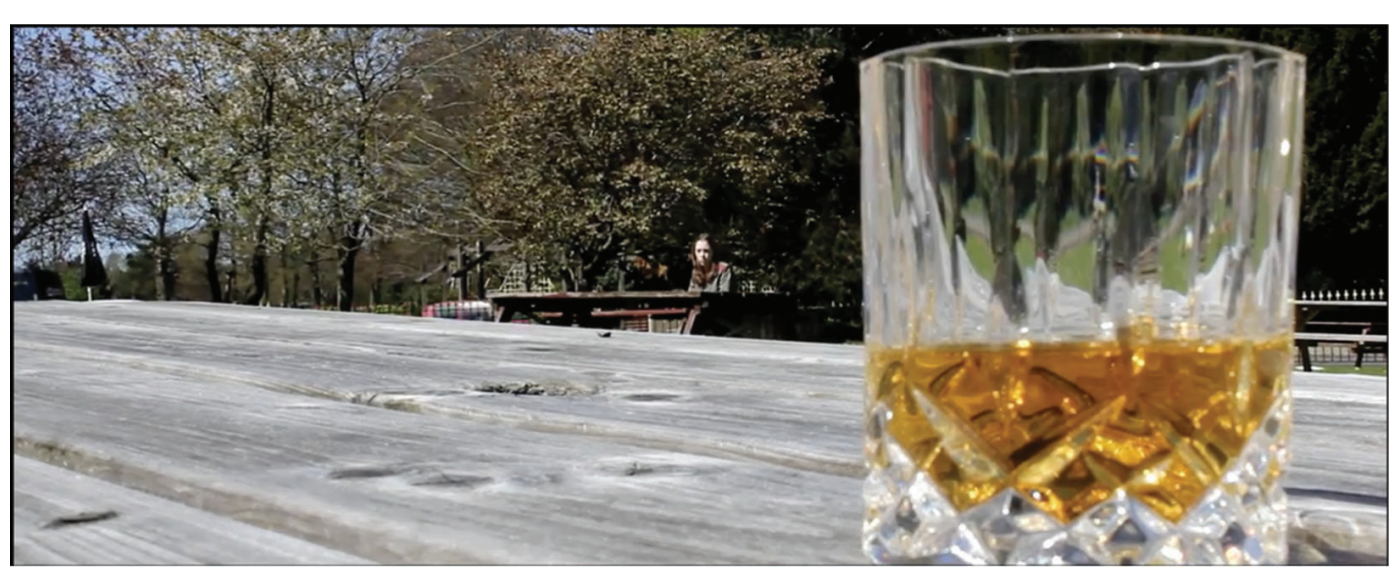

Figure 1: Still from Open Arms, Birkenhead Sixth Form College students, 2015: exploring l'intervalle

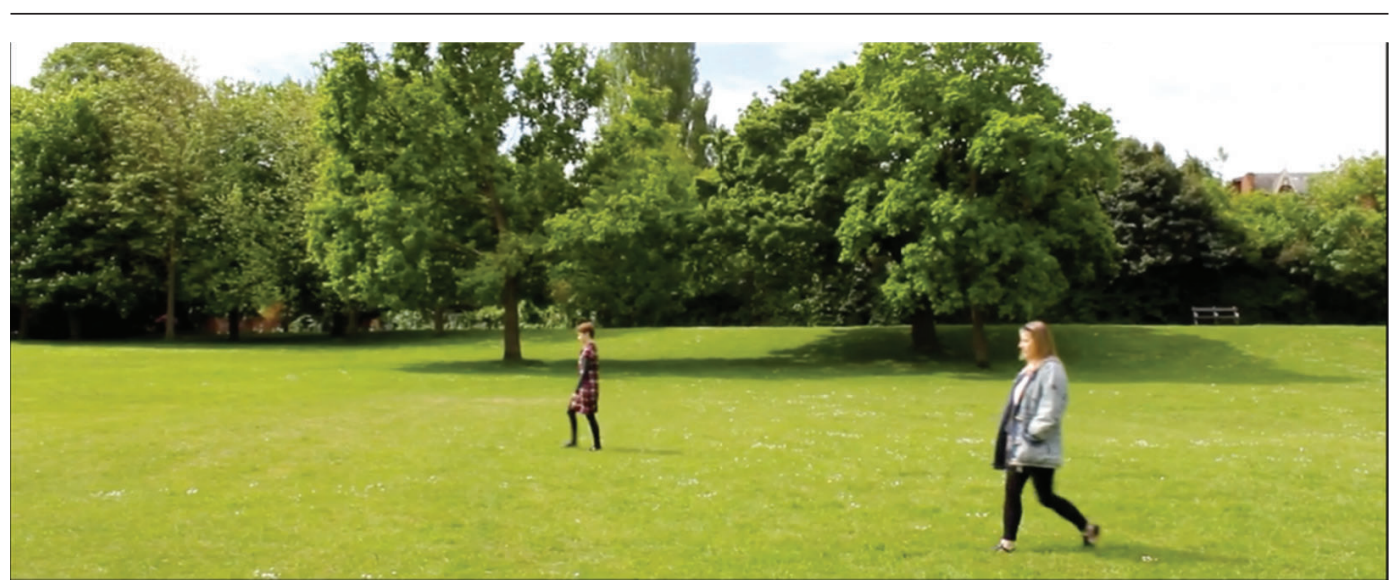

Figure 2: Still from Open Arms, Birkenhead Sixth Form College students, 2015: exploring l'intervalle

This is what the 'cent ans' approach can achieve when it works to maximum effect. In The Cinema Hypothesis, however, Bergala (2016: 43-6) worries that, too often, film teachers or other well-meaning adult gatekeepers may inadvertently (or sometimes knowingly) thwart the aim of participatory practice by insisting on the letter of approved curricula, or by seeing themselves as a co-creator claiming rights over students' taste and work, rather than as an adult opening the door to the possibilities of film-asart, and then stepping aside. In Bergala's cinephilic and administrative world, then, gatekeepers tend to be seen as people who prevent teachers and researchers from hearing and seeing the ideas, opinions and expressive thoughts of children and young people, which are not generally visible or audible in the public sphere.

Given my experiences in the workshops associated with both the Dorothy Project and the 'cent ans' programme, Bergala's division between the passeur, who opens doors, and the gatekeeper, who keeps them closed, seems too stark, too Manichaean. In the remainder of this article, therefore, I reflect on the ethical and pedagogic implications of these two functions for practice-based film education. 


\section{Gatekeepers}

As a researcher undertaking one-off workshops, rather than a regular member of teaching staff in a school or college, I was more than usually reliant on the support and goodwill of gatekeepers - those people or institutions who acted as intermediaries between me and my potential research subjects and workshop participants, identifying and in some cases making the first approach to them, and then managing my access to time and facilities, as well as ensuring the young people's well-being.

The role of such gatekeepers may appear to be less inspirational than that of Bergala's (2016) simultaneously self-revealing and self-effacing passeur, but it is nonetheless important. Ideally, gatekeepers are mindful of the risks of incursion, and intemperate or poorly prepared interventions, especially when potential participants in research and creative activities are being targeted because their life experiences fall outside the mainstream, and may therefore be subject to vulnerabilities, sensitivities and pressures outside an external agent's (researcher, passeur, teacher) personal understanding or ethical practice. By the same token, it may well be that, as a result of those experiences, the research participants have already become, to borrow an illuminating term from the social work literature, 'experts by experience': that is, they will have acquired forms of knowledge and habits of self-preservation that exceed the awareness of their protectors (Preston-Shoot, 2007). In those circumstances, both gatekeeper and the researcher-passeur-teacher will need to accept the eclipse or compromise of their own institutional and aesthetic authority, as Bergala (2016) envisages.

Negotiating the gatekeeping function was, not surprisingly, generally more straightforward for the internationally accredited 'cent ans' workshops than for my independent initiatives in the Dorothy Project. Even so, there were many gatekeepers to deal with: individuals with power over a particular group (a head teacher or subject leader in a school), institutional actors (an education board, a government department, a local council, an ethics committee), and members of the community with a strongly defined sense of leadership and cultural precedence.

In Birkenhead, I had recently become a governor of the college involved, and volunteered to lead the workshop after a discussion about enhancing creative activities for students. The teachers we worked with were self-effacing or generously permissive as the young film-makers moved off in pursuit of spatial confidence and creative ownership. In Menai, where the school had been identified through a contact we had worked with in the Dorothy Project, the arts and photography teacher who was our designated point of contact was personally helpful and engaged, but more constrained by the institutional culture and state law. For example, she was required to enforce rules about access to the internet on the school grounds, which stymied various viewing choices. In addition, the school vetoed entry of the students' film into a national short-film festival, just in case their film might be screened alongside an entry with 'adult content'!

The aim of the Dorothy Project was to discover the imaginative effect of migration on potentially vulnerable young people by observing their responses to commercially or otherwise available films on child migration, as articulated through their own film-making on the topics of travel, transitional objects and transformation. In other words, I was using film as an intervention to afford voice, perspective, consciousness or confidence to the workshop participants. Not only was it right, therefore, that I should engage with institutional gatekeepers, but ethically, it was incumbent on me as researcher to consider a number of factors. Was it in the best interests of my subjects/co-creators 
to be constantly asked to create cinematic or digital responses that related to their social status, lived experience, or some other structural disadvantage (McAreavey and Das, 2013: 116-18)? How could I minimize the potential for re-traumatization in getting them to tell their story (van Os et al., 2018)? Was my approach sufficiently sensitive to their resistance to being cast as the perpetual refugee, rather than just another child or young person who wants to work with film (Clark and Sharf, 2007)? Equally, I could not take it for granted that all my subjects would want to share their stories about migration. Kristin Perry has made the point forcefully in relation to the 'desire for narrative' among researchers studying the experience of being a refugee: 'storytelling and the sharing of personal experiences' are simply not crucial for all refugees (Perry, 2008: 353; Lenette et al., 2015: 1000).

In retrospect, I can see how Bergala's (2016) model offers a useful way of avoiding some of these pitfalls, specifically in the way that he identifies l'altérité ('otherness') as a necessary supplement to the function of the passeur. Rather than the vulnerable young film-maker embodying l'altérité by reason of their biography, it is the visual insights and magic of film itself that create a space of difference and otherworldliness. From this perspective, passeur, teacher and student/participant occupy a horizontal plane of being and doing that is not pre-emptively fissured by experience. Put another way, there is a space within art that affords elements of difference to be imagined as both interior and external to personal stories and self-exposure.

In social action and social services, the discourse of vulnerability can have both positive and negative connotations for those so labelled (Brown et al., 2017). The 'vulnerable' subject risks being seen only as an outsider, and so possibly as a threat, when what is needed in a high-functioning society is agency and participation and, indeed, shared risk (Faulkner, 2011). Overly protective or controlling gatekeepers can use the concept of 'vulnerability' as a mechanism of control, in effect silencing their vulnerable charges (especially young people) by denying them the opportunity to participate in research (Heath et al., 2007). In the context of health research, and while acknowledging that all gatekeepers were 'worthy of respect' as stakeholders, Sixsmith et al. (2003: 589) have observed how sometimes gatekeepers would work 'to their own agenda regardless of legitimacy': 'They could attempt to influence the research process with their own version of "reality" by indicating only participants "approved of" by themselves.' Other examples of imposing an approved reality include attempts to insist on specific methodological approaches, or to suppress findings that do not fit with the gatekeeper's preferred image of a community under scrutiny (George et al., 2014; Bhopal and Myers, 2008). In such circumstances, researchers may be tempted to compromise ethical principles, with the consequence that data and research findings will be compromised, which will in turn devalue the contribution of the research subjects and distort the feedback they receive (Wiles et al., 2006, 2008; Lennie and Tacchi, 2015).

Although the power disparity between researcher and gatekeeper, and between participant and gatekeeper, can be both challenging and constraining, it is important to remember that it can also be dynamic and productive, and as such generate positive energy in research and in creative work (Bhopal and Myers, 2016; Sixsmith et al., 2003). To this end, it is the researcher's responsibility to maintain a fluid and receptive approach, which nonetheless keeps in view the benefit to participants, the ethics of sharing knowledge and experience, and, if push comes to shove, the option of withdrawing when the situation cannot accommodate best practice (López-Bech and Zúñiga, 2017). 
In the Dorothy Project, one of my most positive experiences with gatekeepers was in the workshop with young domestic migrants in Guangzhou. One of the possible local gatekeepers we contacted had undertaken cultural work with children at a municipal arts centre, the Children's Palace. However, it turned out that migrant children did not have access to this local facility and his expertise. In the end, we found that the best way to work with more marginalized children was through religious NGOs set up for that purpose, even though they were themselves somewhat liminal, given the ambivalent status of religion in China. In the end, our gatekeeper was a young man of rural background, himself an internal migrant, who had had some teacher training. As a result, he was personally familiar with the disruptions in the lives of the young people with whom he was working. He determined to afford them space and time to discover the possibilities of learning and of childhood as a joy. His only demand on us as researchers was that we treat the children as we would any other child in China - that is, with respect. His interventions therefore in no way stultified their energetic use of space - rushing madly around the two streets in which they all lived with their new cameras, and in and out of the NGO drop-in centre - or their creative decisions. Rather, he was concerned with their long-term welfare. For instance, he asked us to limit the amount of treats we gave them for after-school nourishment, pointing out that he could not replicate this for other activities, so their expectations would be out of kilter. This was a fair and sensible point. A few parents were also on hand, simply because they lived in the same street as the drop-in centre and so were aware of the children and the film-making excitement, but they also stayed out of the activities (although not always out of shot) as they sat down to chat in the sun after work.

Less positive in terms of interactions with gatekeepers was our experience with the Saturday school for Afghan children in London. We had been referred to this school by a third party who worked in one of the institutions participating in the international project and had an existing relationship of active research and engagement with the overarching Afghan organization that liaised with the school. Initial contact was via email to the director of the Saturday school, with follow-up telephone conversations and referral to the school manager, a British woman who was responsible for the curriculum and academic quality, and who would act as on-site gatekeeper. I was working with a documentarist of Traveller background, who had been trained in social science techniques, and a Chinese postdoctoral researcher, who had already assisted me in Guangzhou. Whereas three of the Guangzhou team had had local language skills, and two had been of southern Chinese heritage, none of us was of Afghan background. Understanding that we were fortunate to be allowed to work with the children and young people in these circumstances, we were as sensitive as possible to parental wishes during the recruitment of participants. This involved accepting younger siblings into the group: some were the same age as the Chinese participants in Guangzhou, 7-12, but younger than we had expected in this iteration (10-14). Parents and older siblings explained that they would prefer that all the children should be doing similar activities, a request that we accommodated immediately. The project ideally required four two-hour sessions with a maximum of 12 participants aged 10-14, beginning with an introduction to narrative within film, through making and editing their own films, and concluding with viewing the end product and discussing and critiquing the work. As the project was very popular, we extended the group to 15 children, including under-10s and a 15/16-year-old boy.

Our experience in this workshop lends weight to Bergala's (2016) worries about institutional gatekeepers undermining the transformative aspirations of the cinephilic passeur. While the participants were talented, lively and committed to the process, 
the gatekeeper was anxious that the sudden introduction of film into the curriculum should cause no disruption. This was problematic, given the need for screening sounds, filming space, creative 'noise' and general letting off steam. Following the first session, the school manager informed us that we would be unable to conduct all four sessions because of internal end-of-term examinations. This may have been an oversight, but it may equally have had something to so with her irritation at our - or rather 'film's' presence in her tightly managed learning domain. The loss of two hours meant that we were unable to edit the films on-site, as originally intended. We decided to show what we had, and to ask the children how they 'would have' edited given time and money. The final session was a lively discussion that yielded valuable feedback and insights.

Some weeks after the end of the study, the school manager contacted us to ask whether we would conduct another session, in which the children could edit their films. They could then be shown at the end-of-year graduation ceremony, which was a celebration of adults' and children's achievements in the previous academic year. Although this was extremely inconvenient, given other commitments - I had by then returned to Australia - we agreed. We saw this as a way of expressing our gratitude to the school that also provided an opportunity for the participants to show their creations to parents and a wider audience. A final session was agreed, including Skype and onsite access between the participants and the researchers.

The school manager provided an editor and facilities to edit the films. Of the original 15 participants, 8 attended; we viewed all the footage, and decided which clips to use. The participants chose a comedy about two ordinary men who, following a lottery win, become fat, greedy and selfish; months later, they spoil a family wedding by eating the wedding cake, upsetting the bride, and provoking her uncle to punish the culprits. The punishment takes the form of a physical beating and much shouting. The film-makers insisted that this depiction of physicality was meant to be lighthearted slapstick, as opposed to a depiction of gratuitous violence. The two 'greedy men' were wearing T-shirts stuffed with cushions to make them look corpulent. Despite time restraints and the participants' inexperience in both filming and editing, the end product was - in our opinion - actually quite good and genuinely funny.

We emailed the completed film to the school manager. Several days later, she called to tell us that she was extremely unhappy with the film. She objected to what she interpreted as physical violence, which she said gave the wrong impression about the organization and the Afghan people within it. She said she was unable to show this film, and asked us to re-edit it, replacing the scenes of violence with 'a moral message' (Donald, 2015: 146). Our participants had expended considerable time and energy on making the films. The final group of editors was particularly invested in the end product. They were proud of their achievement and eagerly anticipating showing it to their families and friends. The film was their creation, made in collaboration with a sensitive editor. We felt that it was wrong to override their decisions, and to censor their message. Moreover, we were not convinced that, as a white British woman, the school manager was qualified to judge what was or was not an appropriate depiction of Afghan people in general, and these children in particular. We noticed that the boy playing the family elder was the 15 year old, and that perhaps he presented on screen as a virile young man rather than as a child, and perhaps this was confusing to the gatekeeper, who saw her role as overseeing children. We were concerned that her objective was to present a graduation ceremony that offered a version of childhood that was unthreatening and unchallenging to British norms, one that reflected well on the organizers' ability to facilitate its continuance, rather than give a voice to Afghan experience and the insights of the young film-makers and actors. 
At the same time, we were conscious of the conflicting obligations of facilitating future access for ourselves and our institutions. We could not divulge to the school manager some of the more sensitive topics raised by the film-making process. Along the way, the young film-makers had toyed with ideas about zombies, family deaths, and terrifying journeys from life to living death, which seemed far more disturbing than the moral fable about greed and (in)appropriate behaviour at a wedding. As academics, we were also sensitive to the inequality of power relationships in play, which as responsible researchers we had striven to redress in our own working relationships with participants, in this case children.

After much discussion, we decided we could not re-edit the film to suit the purposes of a third party not involved in the study, and moreover an adult of a different ethnic origin. We took the view that to do so would breach our ethical obligations. We therefore searched for a compromise. We had created a presentation to give feedback to the participants at the end of the project. This included unedited film clips and particular shots made by participants, along with our comments on the process of filmmaking, and an exploration of what we had said about the concept of 'journey' as it was represented within the participants' films. We showed this to the school manager for her approval, and it was agreed that we would present it at the graduation, as it was about the study, and featured all of the children's work.

At the end of the graduation ceremony, one of the research team was approached by a woman who had been instrumental in founding the school. She had enjoyed the presentation and was pleased it had been uploaded onto our website, so that people all over the world would have an opportunity to learn not only about the children's specific participation in this project, but about the positive aspects of Afghan culture more generally. In her view, the war in Afghanistan had led to very negative media coverage of Afghan people. She was anxious that people should learn that Afghan children were the same as all other children, with the same interests and aspirations, and the ability to participate in the same cultural interests. We felt that her comments vindicated our refusal to re-edit the film, as to do so would have constituted an act of censorship that we did not feel morally, ethically or ethnically qualified to take.

In Guangzhou, NGO workers had shown a similarly positive response when they watched the edited work from the Red Balloon group. They asked if they could put the films on websites, to show off the work of migrant children. We responded that if the children and their parents agreed, then we agreed too. We had gained permission for the final edits, which were produced with the help of a student editor and then returned to the children in Guangzhou on individual CDs and USBs, to be placed on a project website, and we suggested that the NGO did likewise. We were not confident that this procedure would ultimately be followed, but there was little we could do about that.

\section{Conclusion}

I have described here how I incorporated film workshops with young migrants into a research project. I am happy that doing so significantly enriched my engagement with the films that I studied. By the same token, I would argue there is much to be said for making research an integral component of any practice-based film education, in terms of engaging with ideas, and attempting to produce new understanding and new perceptions.

Undertaking such activities with young people deemed vulnerable or 'hard to reach' (although one might more accurately say that mainstream society itself can 
prove 'hard to reach' for migrants) will usually involve some form of negotiation with gatekeepers, whether in the form of institutional ethics committees, or individuals or groups with vested professional, religious or communal interests. This can be a frustrating process, and sometimes gatekeepers will have ulterior and censorious motives. Nevertheless, it would be invidious and deeply unethical to assume that children should always be accessible to the ambitions of researchers and their pet projects. My experience from the Dorothy Project suggests that negotiating with gatekeepers is more likely to be productive if the researcher has a strong set of ethical guidelines and self-management priorities that make it clear when no further compromise is possible. Film-making and creative practice almost always involve a team effort, and this is certainly the case for an unconventional research project with children and young people. The main finding from our studies was that listening and negotiation are paramount responsibilities for researchers. Gatekeepers will present opportunities and challenges, and the participants will themselves produce unexpected results and consequences of research and praxis. This is all grist to the mill as long as the values underpinning the work are made explicit in the research plan and in any institutional process of ethics approval, and as long as three simple ethical principles are adhered to in the conduct of the research: (1) do no harm; (2) show tact and humility in the field; and (3) maintain the capacity to learn from your peers whether participants or gatekeepers.

How do these recollections inflect a reading of Bergala's (2016) approach to film education? First, the gatekeeper may be problematic and seek to constrain and control the film education process and outcomes. As educators, we can learn from our frustration in such circumstances. Even if we cannot always be the ideal passeur, we should remember at least not to be the censor. Second, we should be aware that not all gatekeepers are the enemy of inspiration or freedom. If they are attentive, generative and self-effacing, as they were - impressively - in Guangzhou, and also in Birkenhead, that could be because their motivations are truly generous, because they want to hold open gates to students and young people, or because they too know that there is a world out there to experience, to see and to film. At best, gatekeepers may see their role as helping, supporting and applauding younger people as they step forward with their eyes, their courage, their imaginations and their cameras (Bergala, 2016: 38-9). In the end, the passeur - the ferryman - is also a benign gatekeeper.

It also worth remembering that young people have their own ways of dealing with intrusive or demanding gatekeepers. Two of the groups I worked with came up with remarkably similar strategies that indicate a common child/teen response to thresholds between security and excitement, and between enforced boundaries and secret spaces of escape (Kuhn, 2010: 86; Donald, 2015: 144). They both chose to set key sequences of their films in that quintessentially private/public school space: the girls' loos.

\section{Notes on contributor}

Stephanie Hemelryk Donald is Distinguished Professor of Film and Research Director in the Centre for Culture and Creativity at the University of Lincoln. Recent books include There's No Place Like Home: The migrant child in world cinema (London: I.B. Tauris, 2018); with Emma Wilson and Sarah Wright (eds), Childhood and Nation in World Cinema: Borders and encounters (New York: Bloomsbury, 2017); and, with Christoph Lindner (eds), Inert Cities: Globalization, mobility and suspension in visual 
culture (London: I.B. Tauris, 2014). She is currently working on a special issue on refugee film-making for Alphaville.

\section{Filmography}

L'Arrivée d'un train en gare de La Ciotat (The Arrival of a Train, FR 1896, Auguste Lumière and Louis Lumière)

Le ballon rouge (The Red Balloon, FR 1956, Albert Lamorisse)

Jacquot de Nantes (FR 1991, Agnès Varda)

Rabbit-Proof Fence (AU 2002, Philip Noyce)

The Wizard of Oz (US 1939, Victor Fleming)

Zangiku monogatari (The Story of the Late Chrysanthemums, JP 1939, Kenji Mizoguchi)

\section{References}

Bachmann, A. and Zahn, M. (2018) 'Film education as a multiplicity of practices: A media-ecological perspective'. Film Education Journal, 1 (1), 78-89.

Bergala, A. (2016) The Cinema Hypothesis: Teaching cinema in the classroom and beyond (FilmmuseumSynemaPublikationen 28). Trans. Whittle, M. Vienna: Austrian Film Museum.

Bhopal, K. and Myers, M. (2008) Insiders, Outsiders and Others: Gypsies and identity. Hatfield: University of Hertfordshire Press.

Bhopal, K. and Myers, M. (2016) 'Marginal groups in marginal times: Gypsy and Traveller parents and home education in England, UK'. British Educational Research Journal, 42 (1), 5-20.

Brown, K., Ecclestone, K. and Emmel, N. (2017) 'The many faces of vulnerability'. Social Policy and Society, 16 (3), 497-510.

Cangià, F. (2018) 'Precarity, imagination, and the mobile life of the "trailing spouse"'. Ethos: Journal of the Society for Psychological Anthropology, 46 (1), 8-26.

Clark, M.C. and Sharf, B.F. (2007) 'The dark side of truth(s): Ethical dilemmas in researching the personal'. Qualitative Inquiry, 13 (3), 399-416.

Donald, S.H. (2015) 'Cosmopolitan endurance: Migrant children and film spectatorship'. In Beeler, K. and Beeler, S. (eds) Children's Film in the Digital Age: Essays on audience, adaptation and consumer culture. Jefferson, NC: McFarland and Company, 133-47.

Donald, S.H. (2018) There's No Place Like Home: The migrant child in world cinema. London: I.B. Tauris.

Faulkner, J. (2011) 'Vulnerability and the passing of childhood in Bill Henson: Innocence in the age of mechanical reproduction'. Parrhesia, 11, 44-55.

George, S., Duran, N. and Norris, K. (2014) 'A systematic review of barriers and facilitators to minority research participation among African Americans, Latinos, Asian Americans, and Pacific Islanders'. American Journal of Public Health, 104 (2), e16-e31.

Gibbs, A. (2018) 'Film education otherwise: A response to Bergala's dialectics of cinema and schooling'. Film Education Journal, 1 (1), 90-100.

Heath, S., Charles, V., Crow, G. and Wiles, R. (2007) 'Informed consent, gatekeepers and gobetweens: Negotiating consent in child- and youth-orientated institutions'. British Educational Research Journal, 33 (3), 403-17.

Kuhn, A. (2010) 'Cinematic experience, film space, and the child's world'. Canadian Journal of Film Studies, 19 (2), 82-98.

Lenette, C., Cox, L. and Brough, M. (2015) 'Digital storytelling as a social work tool: Learning from ethnographic research with women from refugee backgrounds'. British Journal of Social Work, 45 (3), 988-1005.

Lennie, J. and Tacchi, J. (2015) 'Tensions, challenges and issues in evaluating communication for development: Findings from recent research and strategies for sustainable outcomes'. Nordicom Review, 36, 25-39.

Lewis, H., Dwyer, P., Hodkinson, S. and Waite, L. (2015) 'Hyper-precarious lives: Migrants, work and forced labour in the Global North'. Progress in Human Geography, 39 (5), 580-600.

López-Bech, L. and Zúñiga, R. (2017) 'Digital storytelling: Putting young asylum seekers at the heart of the story'. Intercultural Education, 28 (2), 224-8.

McAreavey, R. and Das, C. (2013) 'A delicate balancing act: Negotiating with gatekeepers for ethical research when researching minority communities'. International Journal of Qualitative Methods, $12(1), 113-31$. 
Perry, K.H. (2008) 'From storytelling to writing: Transforming literacy practices among Sudanese refugees'. Journal of Literacy Research, 40 (3), 317-58.

Preston-Shoot, M. (2007) 'Whose lives and whose learning? Whose narratives and whose writing? Taking the next research and literature steps with experts by experience'. Evidence and Policy, 3 (3), 343-59.

Reid, M. (n.d.) 'L'Intervalle: 2014/15'. BFI / Cinémathèque blog. Online. https://tinyurl.com/y45jyam4 (accessed 14 February 2019).

Reid, M. (2015) 'In Birkenhead'. BFI / Cinémathèque blog, 26 March. Online. https://tinyurl.com/ yx9u78vc (accessed 14 February 2019).

Reid, M. (2017) 'Illawong'. BFI / Cinémathèque blog, 2 July. Online. https://tinyurl.com/y56p5xqu (accessed 14 February 2019).

Rushdie, S. (1992) 'Out of Kansas'. The New Yorker, 11 May. Online. www.newyorker.com/ magazine/1992/05/11/out-of-kansas (accessed 14 March 2019).

Sixsmith, J., Boneham, M. and Goldring, J.E. (2003) 'Accessing the community: Gaining insider perspectives from the outside'. Qualitative Health Research, 13 (4), 578-89.

van Os, E.C.C., Zijlstra, A.E., Knorth, E.J., Post, W.J. and Kalverboer, M.E. (2018) 'Finding keys: A systematic review of barriers and facilitators for refugee children's disclosure of their life stories'. Trauma, Violence, and Abuse, 1-19. Online. https://tinyurl.com/yas6etzo (accessed 19 January 2019).

Wiles, R., Charles, V., Crow, G. and Heath, S. (2006) 'Researching researchers: Lessons for research ethics'. Qualitative Research, 6 (3), 283-99.

Wiles, R., Prosser, J., Bagnoli, A., Clark, A., Davies, K., Holland, S. and Renold, E. (2008) Visual Ethics: Ethical issues in visual research (ESRC National Centre for Research Methods Review Paper). Southampton: National Centre for Research Methods. 